\title{
Estimating potential impacts of a change in river quality on the tourism value of Kruger National Park: An application of travel cost, contingent and conjoint valuation methods
}

\author{
Jane Turpie ${ }^{1 *}$ and Alison Joubert ${ }^{2}$ \\ ${ }^{1}$ Percy FitzPatrick Institute, University of Cape Town, Rondebosch 7701, South Africa \\ ${ }^{2}$ Dept of Statistical Sciences, University of Cape Town, Rondebosch 7701, South Africa
}

\begin{abstract}
Development and resource allocation decision processes are increasingly under pressure to take environmental values into account in order to reach optimal economic outcomes. In South Africa new techniques will be needed to incorporate environmental values into environmental impact assessment and in the allocation of water resources under the new National Water Act (1998), both of which require the comparison of alternative scenarios with varying impacts on the environment. This study on the tourism value of rivers in the Crocodile Catchment is the first case study to develop methods for incorporating the economic values of the goods and services provided by functioning aquatic ecosystems into such decision processes. Rivers within the Kruger National Park (KNP) will be affected by water usage in the portions of their catchment areas upstream of the park boundary. The current tourism value of these rivers was considered in terms of revenues to KNP (visitors' on-site expenditure), contribution to the economy (visitors' on-site and off-site expenditure) and recreational value, including consumers' surplus. The effect of a change in river quality was determined using a joint contingent valuation - conjoint valuation approach, whereby respondents rated four different scenarios, each containing four attributes at four different levels. It was estimated that the current value of KNP tourism is about $\mathrm{R} 136 \mathrm{~m}$. in terms of on-site expenditure, R267 m. in terms of economic impact, or all expenditure related to visiting the park, and $\mathrm{R} 1 \mathrm{bn}$. in terms of consumers' surplus. The latter two values can be added to calculate total recreational value. Four methods were used to isolate the value of rivers from the total tourism value stated above, and all yielded similar values of about $30 \%$ of the total. This implies that about $30 \%$ of tourism business would be lost if rivers were totally degraded. Thus, rivers within the Crocodile Catchment, which takes $22 \%$ of KNP visitor-nights, contribute R9 $\mathrm{m}$. to KNP revenues and have a total annual recreational use value of about R85 m., including off-site expenditure and consumers' surplus. The conjoint analysis generated an equation which is able to predict the change in trip expenditure, or total KNP revenue, associated with changes in levels of any of the four attributes considered. Appearance of the riverscape has the greatest influence on recreational use value, followed by waterbird diversity, aquatic megafauna and riparian tree density. Such models can be used in water allocation decision processes when attribute levels associated with alternative management scenarios are predicted by aquatic ecologists.
\end{abstract}

\section{Introduction}

Development and resource allocation decisions are usually based on the rationale of maximising economic benefits. Most development carries some degree of impact on the environment, a problem which has been addressed in the past mainly through efforts at damage mitigation, but the economic implications of environmental impacts have largely been ignored in decisionmaking processes. However, with the valuation of environment and biodiversity becoming a growing international field, there is now increasingly a move in the international arena to consider the full costs and benefits of actions in decision processes, as new understanding suggests that many past decisions have been suboptimal.

In South Africa, it is now starting to be recognised that inclusion of environmental economics is important in environmental impact assessment (CSIR, 2000) and in the application of the new National Water Act (Act 36; RSA 1998; Turpie et al., 2000), in which the environment is recognised as a legitimate water user.

Under the National Water Act, allowance is made for the

* To whom all correspondence should be addressed.

西(021) 650-3290; fax (021) 650-3295; e-mail: jturpie@ botzoo.uct.co.za Received 7 September 2000; accepted in revised form 22 March 2001. allocation of an ecological reserve (the quantity and quality of water required by ecosystems to maintain a certain level of functioning), as well as a reserve for basic human needs. Water resources (river reaches, wetlands etc.) will be classified into management classes which will determine their future state of health (ranging from relatively pristine to 'hard-working'). This, in turn, will determine how much water can be allocated to development and how much is retained in aquatic systems as an ecological reserve. The process of definition of management class and reserve has been termed resource-directed measures (RDM). In this process, the management class - or society's desired future health state of the ecosystem - will be decided on the basis of ecological status and health, basic human needs, and economic and social considerations. The framework and methodology for incorporation of socio-economic considerations in the decision process is still under development, but will involve a catchmentlevel analysis of the implications of retaining alternative levels of quantity or quality of water in the ecosystem (Turpie et al., 2000). This decision process will rely on capacity to predict both the ecological and economic impacts of different scenarios of catchment management.

Whereas the field of environmental valuation has progressed significantly during the past two decades, methods for predicting changes in value due to changes in environmental quality are less 
established. Such methods would be appropriate for application in environmental impact assessments as well as resource allocation decisions such as in the RDM process, both of which involve the evaluation of alternative scenarios which have differing levels of impacts on the environment.

This study aims to apply existing valuation techniques to rivers, and to develop a methodology for estimating the economic impacts of a change in river quality. While aquatic systems affected by water allocation decisions yield numerous economic benefits from goods and services (e.g. fisheries, plant harvesting, recreation, flood retention, and water purification), we concentrate on tourism values, particularly as they apply to rivers flowing through a protected area. Isolating the tourism value of specific natural resources is particularly complex as it involves separating the component values of composite goods. Firstly, it is necessary to isolate the value of rivers as one of numerous attractions of a protected area. Secondly, to understand how river values might change with different levels of water allocation, it is important to understand how different attributes of rivers contribute to this value. This is because ecological impacts are described in terms of expected changes in separate components of the ecosystem, many of which respond differently to changes in variables such as river flow.

A case study was carried out within the Kruger National Park (KNP), South Africa. Because the economic implications of water allocation will need to be understood at the catchment level, we concentrated on that part of the Crocodile River catchment falling within the southern KNP. The Crocodile catchment forms part of the Komati basin, and the Crocodile River forms the southern boundary of the KNP.

\section{Methods}

Two survey instruments were developed, one for visitors to the KNP, and another for tour guides within the park. These are described in more detail below. The survey instruments were designed, tested, refined and administered during the week 29 May to 2 June 2000. Visitors to Berg en Dal, Skukuza, Pretoriuskop and Lower Sabie Rest Camps, and Afsaal, Tshokwane and Nkuhlu picnic sites were approached randomly by the enumerators and interviewed. In total, 183 questionnaires were completed. Information gathered in the surveys was used to:

- determine the value of tourism in the Komati Basin and Crocodile catchment areas of the KNP;

- determine the proportion of this value that can be ascribed to rivers; and

- determine the potential effect of a change in river quality on this value.

\section{Determining the value of tourism in the study area}

Several measures of value were considered:

\section{Revenue to KNP}

Visitor data and revenue data were available from the KNP, separated to different gate entries and different rest camps. This revenue was apportioned to the Komati Basin, and within this, the Crocodile Catchment area, using the proportions of visitor entries and overnight revenues accruing to gates and camps within these areas. These statistics give a simple measure of gross income to the $\mathrm{KNP}$ and its component areas in terms of visitor spending.

\section{Contribution to the SA economy}

Some visitor spending outside the park is attributable to the park itself. This is true in the case of visitors paying outside safari operators for guided trips into the park (apart from the entrance fees, this income accrues to companies outside the park), and in the case where visiting the park formed part of the reason for a trip from home (where a portion of the visitors' total travel expenditure is therefore attributable to the park). These values were estimated as follows:

\section{Revenues to private safari companies operating within the KNP}

Information on the tariffs for day safaris was obtained through telephonic interviews with safari companies. Data on the number of clients brought into the park by safari operators and their gate payments was obtained from the KNP. These figures were used to estimate the total annual turnover generated by private safari companies from their operations in the KNP.

\section{Visitor expenditure outside the KNP}

The visitor survey included questions about visitors' origins, full trip itinerary and budget, and the degree to which visiting the KNP was the motivation for the trip. The latter, given as a percentage, was used to attribute the portion of total off-site expenditure attributable to the KNP.

\section{Recreational use value including consumer surplus}

The amount of money that visitors spend on enjoying an amenity such as the KNP may only reflect part of their actual willingness to pay for the experience. The willingness to pay more than the actual price is called consumer surplus. When aggregated over all users, the sum of actual expenditures and consumers' surpluses equals total recreational use value (Fig. 1). This is usually estimated by means of the travel-cost method (TCM, Bockstael et al., 1991). Questions addressing trip costs and on-site expenditure were thus included in the visitor survey.

A zonal TCM was applied, which compares the frequency of visits from zones of different distances to the reserve with the travel costs from each zone to estimate the visitors' demand curve and the consumer surplus (Hof and King, 1992). The origin zones were taken as the different countries and for South Africans, different provinces. Estimated total visitor numbers from each zone were expressed as a proportion of the total zonal population to obtain visitation rates from each zone. In order to avoid the problems of multiple site visits, the travel costs were not taken as full trip costs, but as the proportion of total trip costs that visitors ascribed to the KNP. In order to derive a demand function for visits to the KNP, zonal visitation rates (calculated on the basis of the total population of each zone) were regressed against average travel cost per visitor and GNP per capita in each zone. GNP per capita did not contribute significantly to any regression, but the best functions were obtained when samples from Africa (apart from South Africa and Namibia), South America and India were analysed separately, as visitation rates were disproportionately lower from these zones, possibly due to a combination of large population size, low average wealth, cultural distance and/or availability of closer substitute destinations. The functional form of the travel-cost demand curve, which may be linear, semilog (log of dependent variable) or loglinear (double $\log$ ), and which is most commonly a semilog function, was chosen on the basis of best fit. Thus, the resulting demand curves took the following form, expressed as a semi-log function:

$$
\operatorname{Ln}(Q)=a+b(T C)
$$




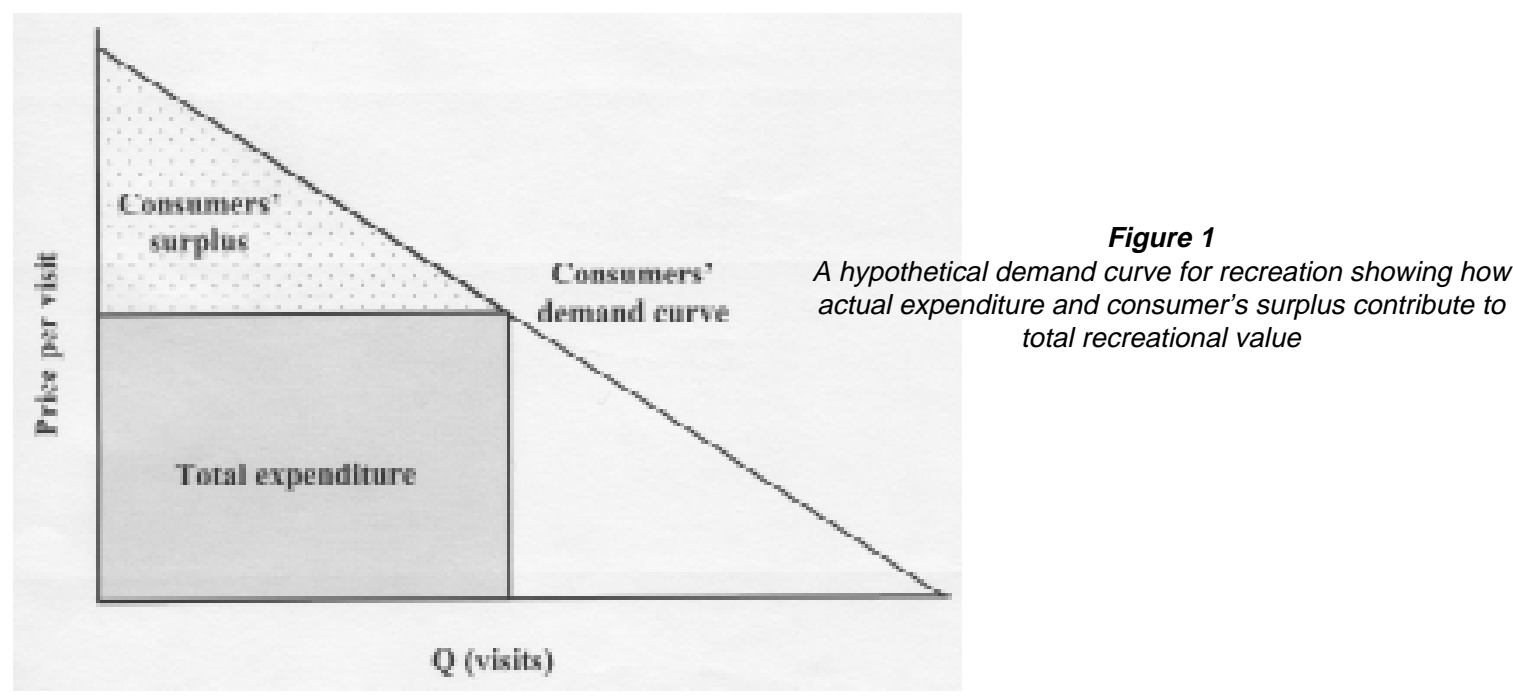

where:

Q is quantity of visits per zonal inhabitant and

$\mathrm{TC}$ is average travel cost per visitor per zone.

Consumers' surplus, was calculated for each zone by taking the integral under the demand function with respect to travel cost (Fig. 1), as follows (Hof and King, 1992):

$$
\mathrm{CS}=-\mathrm{e}^{\mathrm{a}+\mathrm{bTC}} / \mathrm{b}
$$

The area described by this function does not include the actual expenditure by visitors (Fig. 1). Actual expenditure as determined in the surveys was added to consumers' surplus for each zone to obtain total estimated recreational use value.

On-site expenditure, off-site expenditure and consumers' surplus were initially calculated for the whole of the KNP, and were then apportioned to the Komati River basin and Crocodile River catchment portions of the park on the basis of the percentage of visitor nights spent in each of these areas.

\section{Determining the proportion of value ascribed to rivers}

The above values come from the multiple attractions that KNP has to offer, with rivers forming only part of the overall 'package'. The percentage of tourism value which could be attributed to the rivers in the park was assessed in the following four ways, as well as by using contingent valuation methods (see following section):

- The percentage of the total mileage of roads in the park which have been laid along rivers, as a measure of past perception of the relative value of rivers to visitors.

- The percentage of total mileage done in the park which was driven near rivers - visitors were asked to trace the routes they had used on a map, and safari guides were asked to trace their most frequently used routes.

- The percentage of time in the park which visitors spent at rivers - visitors and safari guides were asked to give rough estimates of the percentage time they spent at water-holes or dams, at rivers and in bush habitats.

- The percentage of satisfaction or enjoyment which the visitors obtained from rivers - visitors were asked to estimate the percentage satisfaction that they derived from each of the abovementioned habitats.
Safari guides were also asked about seasonal differences in their routes. The safari guide questionnaire also served to acquire qualitative details about seasonality in the use of river routes, and about the attraction of rivers for tourists. Specifically, they were asked if there were any species that would make a visit to a river worthwhile even if there was only one individual present. In order to determine how much of the game-drive generated turnover could be attributed to rivers in the park, these revenues (net of park entrance fees) were multiplied by the proportion of time that was spent along rivers during safaris.

\section{Determining the impact of river quality on tourism value}

The impact of a change in river quality on tourism value was ascertained by a combination of conjoint valuation (e.g. Green and Ra, 1971; Stevens et al., 2000) and contingent valuation (e.g. Mitchell and Carson, 1989; Arrow et al., 1992) methods. Conjoint methods, often used in marketing, seek to ascertain the relative value of different components of a 'package' of goods, or in this case, the different attributes of a river. Respondents are asked to rank or score a range of scenarios which differ in the state of their attributes. There are two possible approaches: a two-factor evaluation or trade-off approach where only two attributes are considered at one time and a number of attribute combinations need to be considered by each respondent; or multi-factor evaluation where respondents are presented with a combination of all attributes at one time. For this study, a multi-factor evaluation approach was taken, as it is easier to administer, and reflected more realistic scenarios of riverine change. Within multi-factor conjoint analysis, respondent burden grows exponentially with the number of attributes and attribute levels. For this reason, the number of attributes and attribute levels were kept to a minimum while trying to ensure that a representative range of relevant river attributes and attribute levels was used. Four attributes of river systems were selected, namely, number of crocodiles and hippos, number of waterbird species, diversity of the riverscape, and density of riparian trees, and four levels were defined for each (Table 1). The levels of these attributes will vary depending on ecological catchment management practices and are appropriate for use as indicators of change.

With four attributes and four attribute levels, there are 256 possible combinations. Of these, 16 were chosen using an approximation to an extended centre point design (Stewart et al., 1993, page C5). Both a worst case (worst on all attributes) and an ideal case (best on all attributes) were included. The status quo 


\begin{tabular}{|l|l|l|l|}
\hline \multicolumn{4}{|c|}{ Summary of attributes and attribute levels } \\
\hline $\begin{array}{c}\text { Crocodiles \& hippos } \\
\text { (C) }\end{array}$ & $\begin{array}{c}\text { Water birds } \\
\text { (W) }\end{array}$ & $\begin{array}{c}\text { Riverscape/scenery } \\
\text { (R) }\end{array}$ & $\begin{array}{c}\text { Trees } \\
\text { (T) }\end{array}$ \\
\hline None & None & Dry riverbed & No trees \\
\hline One of each & Very few & $\begin{array}{l}\text { Uniform scene: } \\
\text { (for example, all reeds) }\end{array}$ & Few/sparse trees \\
\hline About 10 of each & $\begin{array}{l}\text { About 5 species: } \\
\text { (incl. "common" species } \\
\text { e.g. herons, ducks) }\end{array}$ & $\begin{array}{l}\text { Dominated scene: } \\
\text { (for example, several } \\
\text { habitat types present } \\
\text { but one obviously } \\
\text { dominating) }\end{array}$ & Some trees \\
\hline About 20 of each & $\begin{array}{l}\text { About 15 species: } \\
\text { (incl. interesting, rare } \\
\text { species e.g. Fish Eagles, } \\
\text { Finfoots) }\end{array}$ & $\begin{array}{l}\text { Diverse scene: } \\
\text { (for example, some reed } \\
\text { beds, sand bars, and } \\
\text { exposed rocks) }\end{array}$ & $\begin{array}{l}\text { Plenty of trees: } \\
\text { (including } \\
\text { big/tall/old trees) }\end{array}$ \\
\hline
\end{tabular}

formed one intermediate point, while the remaining 13 intermediate combinations (better and worse than the status quo) were randomly generated using MS Excel's random number generator, eliminating impossible combinations of attributes. The 16 scenarios were distributed among five questionnaire versions, including the status quo scenario in each. Each respondent rated four scenarios (three relative to the status quo). The status quo was included in all five survey versions so that respondents had a benchmark against which to compare the different scenarios (although it was not identified as the status quo to the respondent). This also provided a benchmark for adjusting scores from the five questionnaire versions to an approximately common scale. The pristine (ideal) and heavily degraded (worst case) river scenarios were each only included in one of the five survey versions.

In a multi-factor conjoint analysis, a single rating is given to a combination of attributes of different levels. A rating system for scenario comparison was used where respondents were asked to rate each river scenario using a scale from 1 to 10 , with 1 indicating a scenario yielding very little or no satisfaction, and 10 a scenario providing the most satisfaction. Ratings were used because they indicate the relative benefits associated with each scenario explicitly as opposed to other methods, for example, binary preference models which limit the utility 'benefit' to 1s or 0s (Mackenzie, 1993).

Survey responses where respondents had not co-operated or had clearly not answered the question thoughtfully were excluded from the data analysis. A total of 180 responses were used in the conjoint analysis. This final pool of responses consisted of 38 copies of version A, 34 of version B, 34 of version C, 38 of version $\mathrm{D}$, and 36 of version $\mathrm{E}$.

In order to take into account the scaling effects of the different ranges of scenarios offered in each survey version, mean scores for scenarios from the five survey versions were adjusted so that the status quo score in each version was equal to the status quo score in the version containing the ideal scenario.

The relationship between the different levels of the attributes and the response (score) was examined using a generalised linear version of multiple regression (GENSTAT 5, Version 4.1, 1998). The four attributes (croc/hippo, waterbirds, riverscape, and trees) were entered as terms to be fitted to the response variable, i.e. the score $(\mathrm{Z})$ given to the scenario, as follows:

$$
\text { Utility index }(\mathrm{Z})=\text { constant }(\mathrm{K})+{ }_{1} \mathrm{C}+{ }_{2} \mathrm{~B}+{ }_{3} \mathrm{R}+{ }_{4} \mathrm{~T}
$$

where Croc/Hippo (C), Birds (B) and Trees (T) were continuous variables and riverscape $(R)$ was a categorical variable. This model produced the best fit in comparison to other combinations of designated continuous and categorical variables.

A utility score can be generated from the above model for any combination of attribute values representing riverine conditions. In order to express respondents' utility or preferences in monetary terms, a conjoint approach typically includes a cost variable as one of the attributes. Unlike other conjoint studies where the cost variable refers to the cost of a trip (or 'package'), we could not use this approach because of the highly variable total trip costs involved, and because within a trip, the time cost of visiting a river was not really a cost. Instead, we included two contingent valuation-style questions which provided values for the 'ideal' and 'worst' scenarios relative to the status quo:

- If all of the rivers in the KNP dried up completely, so that there were no crocodiles, hippos or waterbirds present, there were no riverine trees, but everything else in the park were the same, would you spend less time in Kruger Park? Please estimate how much.

- Consider the fact that the rivers in the Park are used upstream, and are presently not in their original state. If, hypothetically, the rivers were to be restored to their original state - that is, they contained high numbers of crocodiles, hippos, waterbirds, etc, diverse habitats, including lots of riverine trees, do you think that you would spend more time in Kruger Park? Please estimate how much.

In order to convert utility scores to monetary values, we regressed the three utility scores for the 'worst', 'status quo' and 'ideal' scenarios against their corresponding value in terms of resultant visitor expenditure (both in terms of average expenditure per trip and total annual revenue generated in the KNP). 

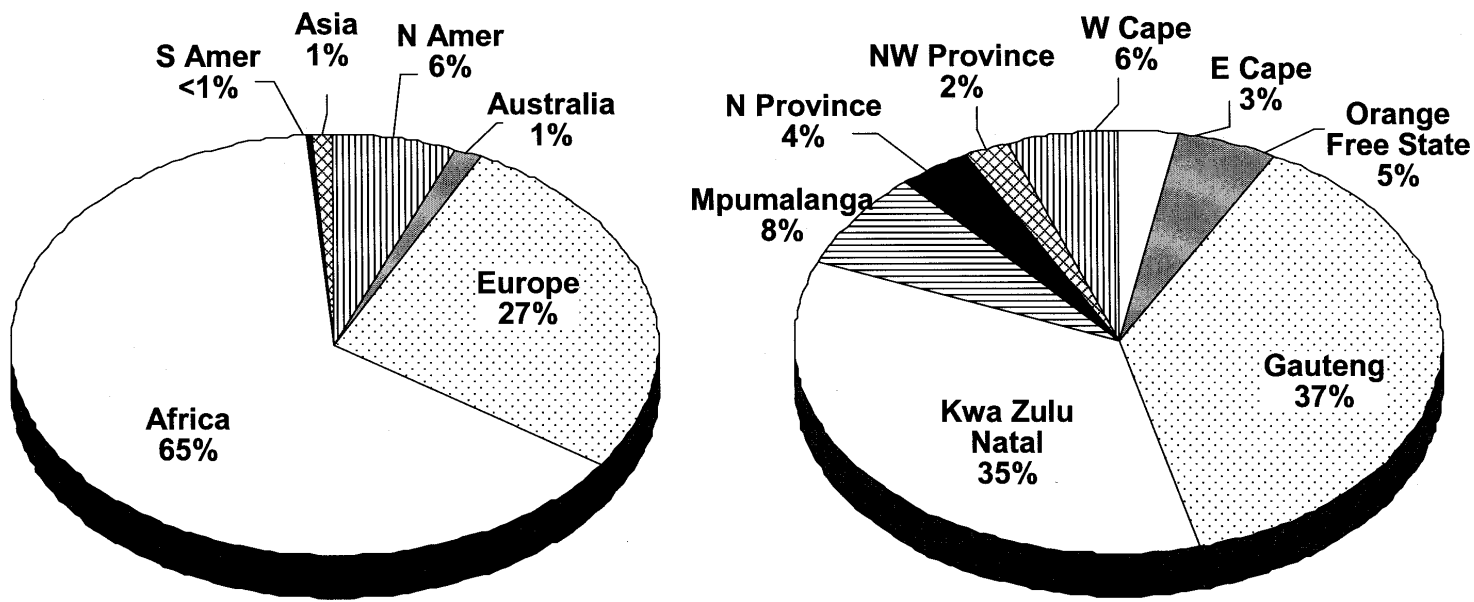

Figure 2

(a) Origin of all visitors, and (b) origin of South African visitors sampled in the KNP during May-June 2000

\begin{tabular}{|l|c|c|}
\hline \multicolumn{2}{|c|}{ TABLE 2 } \\
\hline \multicolumn{2}{|c|}{ Origins and travel costs for visitors to KNP } \\
\hline \multicolumn{2}{|c|}{ South African } & International \\
\hline Percentage of visitor groups surveyed & 72 & 28 \\
Number of groups surveyed & 118 & 45 \\
Number of visitors represented & $431(63 \%)$ & 253 \\
Average group size & 4 & 4.3 \\
Average (median) length of total trip & $10(9) \mathrm{d}$ & $24(15) \mathrm{d}$ \\
Average budget for whole trip (per person) & $\mathrm{R} 1708$ & $\mathrm{R} 13865$ \\
Average (median) length of stay in KNP & $6.8(5) \mathrm{d}$ & $4.9(3) \mathrm{d}$ \\
Average on-site expenditure in KNP (per person) & $\mathrm{R} 860$ & $\mathrm{R} 1849$ \\
$\%$ importance of KNP in whole trip & $85 \%$ & $51 \%$ \\
Inferred on-site + off-site expenditure attributable to KNP (per person) & $\mathrm{R} 1230$ & $\mathrm{R} 5065$ \\
\hline
\end{tabular}

\section{Results}

\section{Visitor origins}

The results of 163 visitor groups (of the total of 183) who supplied information on expenditure were analysed, representing 708 visitors to the park. Of these 11 groups were on bus tours, and the remaining groups were self-drive visitors. $60 \%$ of the visitors (including the group totals) surveyed in the park were from Africa, 29\% from Europe and $6 \%$ from North America (Fig. 2). Visitors from Asia, Australasia and South America each made up less than $1 \%$ of the total visitors to the park. Of the African visitors, South Africans made up $98.9 \%$ of the total, with Gauteng (37\%) and KwaZuluNatal residents (35\%) comprising the majority (Fig. 2). The origin of visitors has not been recently determined in the park, but our sample is assumed to be representative.

\section{Visitor expenditure}

The majority of South Africans visiting the park were on a singledestination trip, with KNP being cited as $85 \%$ of the motivation for their trip away, on average (Table 2). Most international visitors, on the other hand, were on multiple-destination trips, and cited $\mathrm{KNP}$ as being approximately $51 \%$ of the reason for their trip. Total trip costs for foreigners were generally higher than those of South Africans (Table 2). Foreigners tended to spend less time in the KNP, but spent more money on site than did South Africans (Table 2).

According to park statistics, the total revenue generated by visitors' on-site expenditures in the KNP for the 1999/2000 financial year was R136 m. Based on the stated importance of the KNP for a visitor's whole trip away, the inferred willingness to pay (or total on-site plus off-site expenditure attributable to the KNP) is substantially higher than actual on-site expenditure, particularly for international visitors (Table 2). Based on these data, the total expenditure attributable to KNP is estimated to be R267 m. (Table 3 ). Although this includes airfares and tour costs paid outside the country, much of the total probably contributes to the South African economy. Approximately R58 m. was attributed to the Crocodile catchment, of which about $\mathrm{R} 30 \mathrm{~m}$. was on-site expenditure (Table 4).

In addition to the expenditure by self-drive and touring visitors, many visitors enter the park in safari vehicles which operate from various bases around the park. Although their entrance fees are 


\begin{tabular}{|c|c|c|c|c|c|}
\hline \multicolumn{6}{|c|}{$\begin{array}{c}\text { TABLE } 3 \\
\text { Calculation of total visitor expenditure attributable to the KNP }\end{array}$} \\
\hline & $\begin{array}{l}\text { KNP costs } \\
\text { from sample }\end{array}$ & $\%$ & $\begin{array}{c}\text { Estimated total } \\
\text { annual expenditure } \\
(1999 / 2000)\end{array}$ & $\begin{array}{l}\text { Ratio of } \\
\text { total cost } \\
\text { attributable } \\
\text { to KNP to } \\
\text { KNP costs }\end{array}$ & $\begin{array}{l}\text { Estimated total } \\
\text { annual KNP plus } \\
\text { off-site expenditure } \\
\text { attributable to KNP }\end{array}$ \\
\hline $\begin{array}{l}\text { South African } \\
\text { International } \\
\text { Total }\end{array}$ & $\begin{array}{l}240697 \\
165434 \\
406132\end{array}$ & $\begin{array}{l}59 \\
41\end{array}$ & $\begin{array}{c}\text { R80 478 } 966 \\
\text { R55 } 314227 \\
\text { R135 793 193 }\end{array}$ & $\begin{array}{l}1.4 \\
2.7\end{array}$ & $\begin{array}{l}\text { R115 } 103637 \\
\text { R151 } 523288 \\
\text { R266 626 926 }\end{array}$ \\
\hline
\end{tabular}

\begin{tabular}{|l|c|c|c|}
\hline \multicolumn{4}{|c|}{$\begin{array}{c}\text { TABLE 4 } \\
\text { Calculation of visitor expenditure attributable to the Komati Basin area } \\
\text { within the KNP, and within that, the Crocodile catchment area }\end{array}$} \\
\hline & $\begin{array}{c}\text { Percentage of } \\
\text { total KNP visitor } \\
\text { nights }\end{array}$ & $\begin{array}{c}\text { On-site } \\
\text { expenditure }\end{array}$ & $\begin{array}{c}\text { On-site and } \\
\text { off-site } \\
\text { expenditure }\end{array}$ \\
\hline $\begin{array}{l}\text { Whole of Kruger } \\
\text { Komati Basin } \\
\text { Crocodile catchment portion }\end{array}$ & 100 & $\begin{array}{c}\text { R135 793 193 } \\
\text { R83 377 021 } \\
\text { R29738 709 }\end{array}$ & $\begin{array}{c}\text { R266 626 926 } \\
\text { R163 708 933 } \\
\text { R 58 391 297 }\end{array}$ \\
\hline
\end{tabular}

\begin{tabular}{|l|c|c|c|}
\hline \multicolumn{4}{|c|}{ TABLE 5 } \\
\hline Zone & $\begin{array}{c}\text { Average travel } \\
\text { cost/visitor }\end{array}$ & Zone & $\begin{array}{c}\text { Average travel } \\
\text { cost/visitor }\end{array}$ \\
\hline Angola & R1 000 & Sweden & R3 333 \\
Argentina & R2 623 & Switzerland & R2 993 \\
Australia & R3 366 & UK & R6 106 \\
North America & R6 254 & Northern Province & R306 \\
France & R10191 & Western Cape & R2 295 \\
Germany & R6 859 & North West & R1 469 \\
Holland & R2 220 & Eastern Cape & R1 486 \\
India & R4 897 & KwaZulu Natal & R2 006 \\
Namibia & R857 & OFS & R876 \\
Poland & R8 625 & Gauteng & R1 087 \\
Singapore & R2 285 & Mpumalanga & R721 \\
\hline
\end{tabular}

captured in the above statistics, their payments to safari companies are not. In total, 41442 people were brought to the southern KNP by private safari operators from March 1999 to February 2000, on 5694 safari trips (averaging 7.3 clients per vehicle). These figures are for the five gates within the Komati Basin area, but accounted for nearly all $(98.7 \%)$ private safari vehicles entering the park. Private safaris generate an annual gate turnover to KNP of R3 063 840, from entrance fees of R65 per person.

Based on the average price for a half-day game drive of R375, and subtracting the gate fees of R65 per person, the gross income to private safari operators from game drives in the KNP was approximately R12.5 m. In comparison, KNP-run game drives yielded an income of R4.6 m. during the 1999/2000 financial year, from a total of 66507 park guests (included in the estimated expenditure within the KNP, Table 4).

\section{Total recreational use value}

The average travel costs incurred per person in visiting the KNP ranged from R341 to over R10 000 for visitors from different zones (Table 5). Two demand curves were derived, one for 'developing world visitors' and one for 'developed world visitors', the latter including South Africa and Namibia (Fig. 3), although the 'developing world' regression is only significant at the $10 \%$ level. The demand equations can be expressed as follows: 
TABLE 6

Estimates of the total tourism value of rivers based on expenditure in KNP (on-site costs), off-site expenditure (including money paid to safari companies), and consumer surplus

\begin{tabular}{|c|c|c|c|c|}
\hline & \multicolumn{2}{|c|}{ Expenditure } & \multirow{2}{*}{$\begin{array}{l}\text { Consumer } \\
\text { Surplus }\end{array}$} & \multirow{2}{*}{$\begin{array}{l}\text { Total } \\
\text { Value }\end{array}$} \\
\hline & On-site costs & Off-site costs & & \\
\hline Kruger Park & R41 210518 & R41 987765 & R301 200000 & R384 398000 \\
\hline Komati Basin & R25 013106 & R27 309779 & R183 732000 & R236 055000 \\
\hline Crocodile Catchment & R8 921613 & R9 740784 & R65 962800 & R84 625000 \\
\hline
\end{tabular}

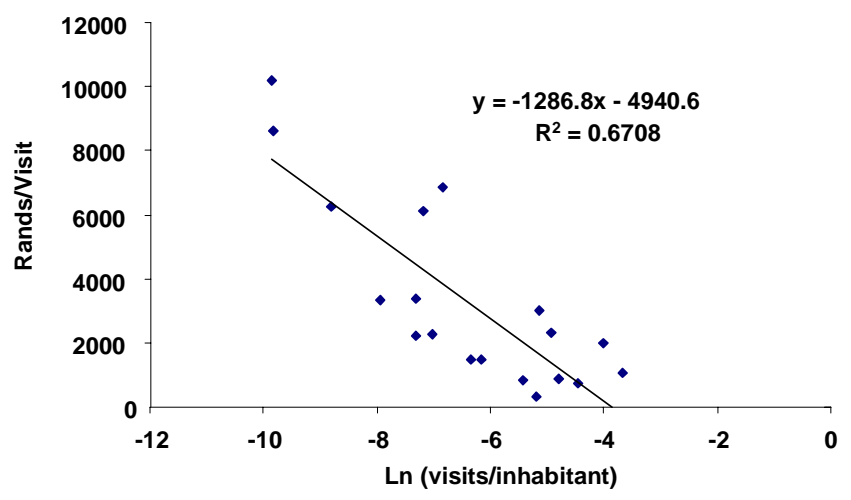

Figure 3

Demand curve for visits to the KNP

'Developed world': $\ln ($ Visitation rate $)=-4.6922-0.0005(\mathrm{TC})$ $\left[\mathrm{n}=19, \mathrm{r}^{2}=0.67, \mathrm{P}<0.001\right]$

'Developing world': $\ln$ (Visitation rate) $=-7.5393-0.0009$ (TC) $\left[\mathrm{n}=3, \mathrm{r}^{2}=0.99, \mathrm{P}=0.06\right]$.

Using the first regression, consumers' surplus is estimated to be at least R1.004 bn., although the total is R.1.016 if both regressions are used. Thus, the Komati basin and the Crocodile catchment area are estimated to contribute approximately R612 m. and R220 m. to this consumers' surplus, respectively.

Among South African visitors, consumers' surplus ranged from R368 to R5 035, with an average of R2 012 and a median of R1 270 per trip. Among foreign visitors, consumers' surplus ranged from R554 to R9 818, with an average of R4 327 and a median of R2 386 per trip.

\section{The tourism value of rivers in the KNP}

In southern KNP, approximately $28 \%$ of the existing road network is along rivers, whereas $32 \%$ of the distance travelled by visitors was along rivers. The percentage of satisfaction gained from rivers $(30 \%)$ was higher than the visitors' estimates of percentage of time spent along them $(25 \%)$. Based on the measure of satisfaction (see discussion), R41 m. (30\%) of KNP revenues and R80 m. of overall expenditure (on-site and off-site attributed to KNP) by tourists could be attributed to rivers for the whole of the KNP. The values apportioned to the Komati basin and the Crocodile catchment, estimated on the basis of total values obtained in the previous section, are summarised in Table 6 .
In addition to the above, responses were obtained from 24 safari guides operating within the KNP. About $27 \%$ of the route driven by guides, on average, is along (or over) rivers. These guides claimed to spend, on average, $26 \%$ of their time at rivers (as compared to $23 \%$ at water-holes and $51 \%$ in the bush). Thus, selfdrive tourists tend to use a greater proportion of river roads than available, while safari guides use less. There was no significant difference in the use of these habitat types in summer or winter. Based on percentage of time spent at rivers, it is estimated that approximately R3.2 m. of the revenues generated outside the KNP for safaris into the park can be attributed to rivers.

Safari guides indicated that a number of attractions justified spending time driving along rivers. The most important of these were the presence of hippos and crocodiles and concentrations of various game species along the river, particularly during the winter months. More than $90 \%$ of drivers felt that the presence of these animal species and the animal concentrations was the most important feature of rivers. Approximately two thirds of the drivers recognised the appeal of the riverscape itself as an attractive feature while around half felt that the large river trees and riverine birds were important features. Safari guides also indicated that a number of other specialist species such as bushbuck Tragelaphus scriptus, nyala Tragelaphus angasii and, in particular, leopard Panthera pardus were also important and attractive features of riverine areas. Most safari guides did not consider the presence of alien aquatic weeds to be a significant deterrent to visits.

\section{Effect of a change in river quality on tourism value of rivers}

Average scores given for the different scenarios posed to respondents ranged from 1.05 for the 'worst' scenario to 9.45 for the 'ideal' scenario (Table 7). The status quo condition of rivers in KNP scored an average of 8.67 across all five survey versions. After rescaling the scores, the status quo scored 7.71, and the scores ranged from -0.68 for the 'worst' to 9.45 for the 'best' scenario.

The utility score $(\mathrm{Z})$, was predicted on the basis of attribute levels by the generalised linear model $\left(r^{2}=0.671\right.$, Table 8$)$ :

$$
\begin{aligned}
& \mathrm{Z}=0.142+0.0985 \mathrm{C}+0.2251 \mathrm{~B}+(0.703 \text { if } \mathrm{R} 2 \text { or } 2.236 \text { if } \mathrm{R} 3 \\
& \text { or } 2.371 \text { if } \mathrm{R} 4)+0.0629 \mathrm{~T}
\end{aligned}
$$

The $\mathrm{Z}$ score of the status quo was equated with the current expenditure of tourists in the KNP as follows. Currently, visitors spend an average of R308.80/d (this study), and spend R1 544 within the KNP on a typical trip (based on the survey median of $5 \mathrm{~d})$. The status quo revenues generated by the KNP for the year 1999/2000, were R136 m. For the 'ideal' and 'worst' scenarios, 
TABLE 7

Survey versions and their corresponding scores and values for each scenario (1-4)

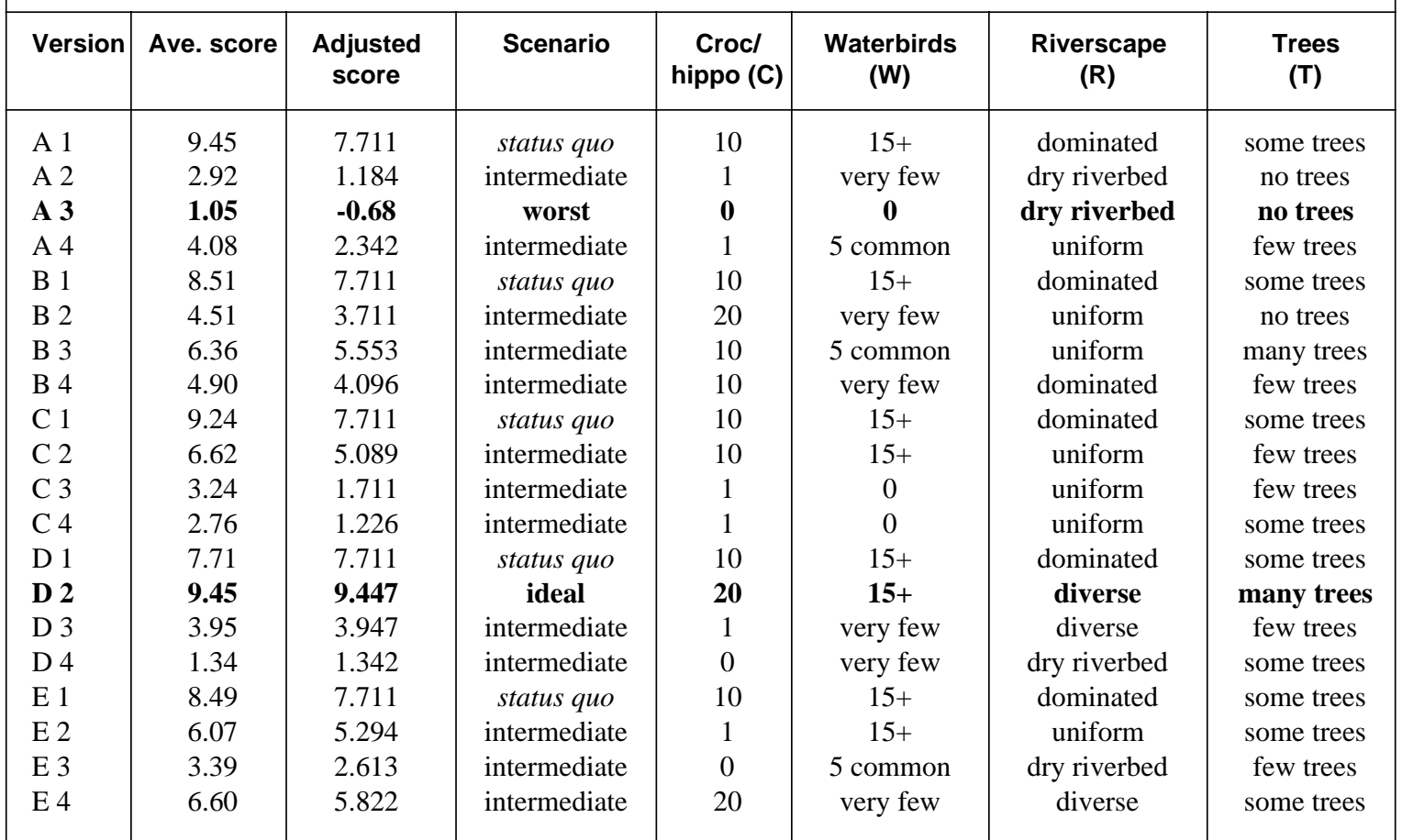

\begin{tabular}{|l|c|c|c|c|}
\hline \multicolumn{5}{|c|}{$\begin{array}{c}\text { TABLE 8 } \\
\text { Summary of parameters for the conjoint model, and summary statistics }\end{array}$} \\
\hline & $\begin{array}{c}\text { Co-efficient } \\
\text { estimate }\end{array}$ & Standard error & $\mathbf{t}(713)$ & P \\
\hline Constant & 0.142 & 0.167 & 0.85 & 0.394 \\
Croc C & 0.0985 & 0.0138 & 7.13 & $<.001$ \\
Birds C & 0.2251 & 0.0167 & 13.51 & $<.001$ \\
Scape 2 F & 0.703 & 0.223 & 3.15 & 0.002 \\
Scape 3 F & 2.236 & 0.281 & 7.96 & $<.001$ \\
Scape 4 F & 2.371 & 0.312 & 7.61 & $<.001$ \\
Trees C & 0.0629 & 0.0105 & 6 & $<.001$ \\
\hline
\end{tabular}

TABLE 9

Condition and value parameters of rivers in three cases

\begin{tabular}{|l|c|c|c|c|c|c|c|c|}
\hline Condition & $\begin{array}{c}\text { Typical amount } \\
\text { of time }\end{array}$ & $\begin{array}{c}\text { Value of (R) } \\
\text { one trip }\end{array}$ & $\begin{array}{c}\text { Annual value } \\
\text { (R) }\end{array}$ & $\begin{array}{c}\text { Utility index } \\
\text { (Z) }\end{array}$ & C & W & R & T \\
\hline Ideal & $+24 \%$ & R 1 917 & R 168635589 & 9.75 & 20 & 15 & 4 & 30 \\
Status quo & $5 \mathrm{~d}$ & R 1 544 & R 135 793 000 & 7.68 & 10 & 15 & 3 & 15 \\
Worst & $-29 \%$ & R 1 094 & R 96 173 207 & 0.37 & 0 & 0 & 1 & 0 \\
\hline
\end{tabular}




\begin{tabular}{|c|c|c|c|c|c|c|c|c|c|}
\hline \multicolumn{10}{|c|}{$\begin{array}{l}\text { TABLE } 10 \\
\text { Scores, attribute levels and Rand values in terms of on-site expenditure (KNP revenue) of example } \\
\text { scenarios. The percentage change in trip value can similarly be used to estimate the change in total } \\
\text { on-site plus off-site expenditure, and in consumer surplus. }\end{array}$} \\
\hline \multirow[t]{2}{*}{ Scenario } & \multirow[t]{2}{*}{ Z score } & \multirow{2}{*}{$\begin{array}{l}\text { Crocs } \\
\text { /hippo }\end{array}$} & \multirow[t]{2}{*}{ Birds } & \multirow{2}{*}{$\begin{array}{l}\text { River- } \\
\text { scape } \\
\text { level }\end{array}$} & \multirow[t]{2}{*}{ Trees } & \multirow{2}{*}{$\begin{array}{l}\text { Average } \\
\text { expenditure } \\
\text { per trip }\end{array}$} & \multicolumn{3}{|c|}{ Annual Value (x1000) } \\
\hline & & & & & & & $\begin{array}{l}\text { Whole } \\
\text { KNP }\end{array}$ & $\begin{array}{c}\text { Komati } \\
\text { basin }\end{array}$ & $\begin{array}{l}\text { Crocodile } \\
\text { catchment }\end{array}$ \\
\hline Status quo & 7.7 & 10 & 15 & 3 & 15 & R 1660 & R145 994* & R89 640 & R31 972 \\
\hline Scenario 1 & 7.3 & 9 & 14 & 3 & 14 & R 1629 & R143 243 & R87 951 & R31 370 \\
\hline Scenario 2 & 8.1 & 11 & 16 & 3 & 16 & R 1691 & R148 744 & R91 328 & R32 574 \\
\hline Scenario 3 & 3.1 & 5 & 5 & 2 & 10 & R 1288 & R113 321 & R69 579 & R24 817 \\
\hline
\end{tabular}

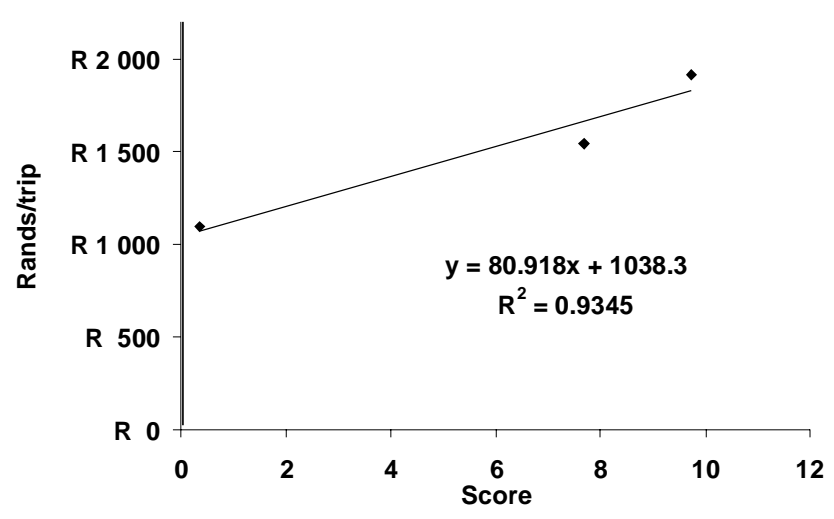

Figure 4

Relationship between utility indices and expenditure per trip for tourism in the KNP

estimates were obtained from the contingent valuation questions in the visitor survey (Table 9). If all of the rivers in the KNP were restored to a 'pristine' state, the average respondent claimed they would spend an average of $24 \%$ more time in the KNP. A typical trip would then have a value of R1 917, and annual revenues would increase to R169 m. In contrast, if the rivers were allowed to dry up and degrade completely, an average visitor would spend $29 \%$ less time in KNP. This visitor, on a typical trip to the KNP, would then only spend a total of R1 094. The annual revenues of the KNP would fall to R96 m. (Table 9).

Based on these three scenarios, the relationships between utility and trip expenditure (Fig. 4) can be expressed as follows:

Visitor expenditure per trip $=1038.3+80.92 \mathrm{Z}\left(\mathrm{r}^{2}=0.94\right)$

Similarly, the equation can be expressed in terms of total KNP revenues as:

Total KNP Revenue $=91316474+7116661 \mathrm{Z}\left(\mathrm{r}^{2}=0.94\right)$

These equations could similarly be adapted to estimate the total willingness to pay (including consumer surplus) on the basis of utility.

Using the relationships between river attributes and utility and between utility and expenditure, the expected changes in total expenditure for any combination of attribute levels can be estimated as exemplified in Table 10.

\section{Discussion}

\section{Measuring tourism value}

Three components of recreational value were considered in this study: on-site expenditure (i.e. within KNP), off-site expenditure (attributable to the resource under consideration) and consumer surplus. In various combinations, these components make up three common concepts or measures of value: revenues (on-site expenditure), contribution to the economy (on-site plus off-site expenditure) and total recreational value (on- and off-site expenditure plus consumer surplus). All three measures are valid in different contexts. They differ mainly in terms of whose benefits they reflect. On-site expenditure reflects the benefits to the protected area authority, but total expenditure reflects the income generated in the economy as a whole. In both these cases, there is a knockon effect (the multiplier effect), in which these expenditures lead to further spending in other sectors of the economy, although we have not attempted to measure this value here. Total recreational value is the value of the experience to the visitor, expressed as the total amount he would have been willing to pay for that experience. Both measures of expenditure reflect proven willingness to pay, while consumer surplus reflects additional willingness to pay which has not been captured in existing markets.

On-site expenditure is the most straight-forward measure of value, and is the most commonly used figure in most analyses of environmental value. This measure of value has important uses, but used in isolation, can be misleading in terms of the value of natural amenities. Indeed, on-site expenditure may be only a small proportion of total economic impact and of total recreational value. This is particularly true in cases where natural amenities are severely under-priced or where access is free. Even in the KNP, where prices are relatively high compared to other natural areas in South Africa, on-site expenditure accounted for about $50 \%$ and $22 \%$ of total expenditure and total recreational value, respectively. In cases where access to resources is free, analyses of off-site expenditure have been a necessary step in elucidating at least part of the magnitude of the recreational value of certain amenities (e.g. recreational shore-fishing, McGrath et al., 1997).

Off-site expenditure involved in recreational use of an amenity is usually estimated by means of questionnaire surveys about travel 
costs, and may or may not be part of a full TCM study which estimates consumers' surplus. However, the estimation of travel costs and their use in demand curve estimation has been notoriously difficult because of the problem that many respondents are on multiple-destination trips. In such cases, full trip expenditure cannot be attributed to the site being valued. In this study, we addressed this frequent problem of overestimation of travel costs by asking respondents to state a percentage of the reason for their trip that was attributable to the KNP. Respondents appeared to have no trouble understanding this concept and responding to the question. We believe that it is possible to obtain relatively robust estimates of off-site expenditure attributable to visiting a natural amenity using this relatively simple technique. However, it should be noted that in this study the survey was carried out entirely on weekdays during winter and may not have been entirely representative of the proportions of visitors on different types of trips or travelling from different distances. For example, it would have been biased against local visitors (weekenders) and those who visit KNP during school holidays (foreigners and locals) or in summer (e.g. birdwatchers).

The estimation of total recreational use value also requires an estimate of consumers' surplus, the latter being most commonly estimated by means of the TCM (Bockstael et al., 1991; Tobias and Mendelsohn, 1991; Dobbs 1993; Freeman 1993; Navrud and Mungatana 1994). In this study, consumer surplus for tourism in the whole of KNP was estimated to be in the order of R $1 \mathrm{bn}$. When compared with the estimated US $\$ 450 \mathrm{~m}$. consumer surplus for all of Kenya's national parks (Moran, 1994), our estimate (about a third of this value) appears to be reasonable.

The accuracy of any estimate of consumers' surplus depends on how well the model can explain variability in visitation rates. In this study, $67 \%$ of the variance could be explained by travel costs. Our model did not take socio-economic factors such as income and differential spending power into account.

\section{Isolating the value of rivers}

Tourists are attracted to the KNP by multiple features which form part of the 'package' for which they are willing to pay. Because of the inter-relatedness of natural features, it can be difficult to isolate the component values. Since wildlife is the main attraction for most visitors to the park, it may be argued that it is not rivers that are being demanded per se, but the wildlife that they support. Thus, rivers could be viewed as supplying wildlife, the real item being demanded by tourists. The same might apply to other habitats. However, because some utility is derived from the plants and the views of the habitats themselves, it would be very complex to approach valuation in this way. Thus, it is important to stress that in this study we view rivers as ecosystems containing wildlife, rather than as the water that sustains wildlife, and thus as commodities which are demanded by tourists.

We experimented with different ways of isolating the value of rivers in the tourists' experience. These included the proportion of roads along the river, the proportion of mileage travelled by tourists along rivers, time spent along rivers, and stated satisfaction gained along rivers. The results from all four methods were similar. Nevertheless, the level of satisfaction was considered to be the most appropriate measure of the percentage contribution of rivers to the total value of visitors' experience in the KNP as it was a direct measure of utility. Furthermore, this measure was least subject to the inherent bias of the position of the existing road network. In addition, the result was supported by the contingent valuation questions concerning a decrease in the time that visitors would be willing to spend in the park if rivers no longer flowed at all, also about $30 \%$. However, not all respondents felt comfortable with, or could answer the more hypothetical contingent valuation question, and if this method were to be used in future, careful attention should be paid to the wording of the question.

\section{Estimating economic impacts of changes in river quality}

Stated preference elicitation methods are usually used to value changes in environmental quality. These methods include contingent valuation, contingent ranking, polychotomous choice and conjoint analysis (e.g. Stevens et al., 2000). The contingent valuation method (CVM) is widely used to evaluate non-market environmental amenities (Mackenzie, 1993; Stevens et al., 2000; Shultz et al., 1998). However, CVM is viewed with scepticism and its accuracy continues to be a subject of debate (Bishop et al., 1995; Boxall et al., 1996; Stevens et al., 2000).

Conjoint analysis is a market research technique which is able to extract preferences for multiple attributes at multiple levels (Boxall et al., 1996), a complexity that reflects the complexity of ecological systems. Conjoint analysis makes substitutes explicit and this may encourage respondents to explore their preferences in more detail as well as to express ambivalence or indifference directly, reducing non-response and protest behavior (Stevens et al., 2000). When a visitor is considering a combination of river attributes for rating or ranking, his decision is governed by tradeoffs, and although he or she may be unable to articulate them, they may be revealed by choices among hypothetical rivers having qualities which are varied in systematic ways.

In this study, the conjoint analysis assessed how the tourism value of the KNP would change in response to changes in river quality as depicted by the changes in level of selected attributes. Although many river attributes may contribute to a visitor's experience, it was necessary to select a limited set of these, in order to minimise the respondent burden and sample size requirements.

Thus, in selecting attributes we tried to choose those which would be both good indicators of river quality and important attributes in terms of the tourist experience. To a large extent, our attributes matched those named by tour guides using the park. However, based on their comments, large mammals, especially leopards, should possibly also have been included.

In this study the different levels assigned to attributes were set relatively arbitrarily, but in applied studies they should be as compatible with the scenarios under study as possible. In addition, our survey was slightly ambiguous in the description of levels of trees, in that the words 'few' and 'some' were chosen to represent two different categories of tree densities. Future survey design should be done in close collaboration with ecologists and hydrologists for the choosing of attributes and attribute levels. For example, in a comprehensive analysis of alternative water allocation options, ecologists will need to be able to predict the changes in levels of such attributes in response to changes in flows. As long as definable scenarios can be associated with each potential management option, decision-making will be better informed.

Adrawback of the conjoint method is that it requires a relatively large sample size. In this study, a sample size of 180 was sufficient to obtain a highly statistically significant model for predicting utility on the basis of attribute levels. However, if further attributes are added in future studies, the sample size will have to be increased.

Conjoint analysis usually includes a monetary attribute, which is then also traded off against other attributes. In this case, trip costs 
could not be included as a variable, and so monetary values were estimated with the contingent valuation question. Thus, instead of calculating monetary values of attributes in a single model, two models were developed in this analysis, the first modelling the utility score, given a combination of four attribute levels (the conjoint model), and the second modelling the monetary value associated with that score (the contingent value model). In this study, utility scores were converted to monetary values on the basis of a regression from only three data points (for the status quo, worst, and best scenarios). The best fit model to these points reflected bigger increases in monetary value at higher attribute levels than at lower attribute levels. This was counter-intuitive, especially given expectations of diminishing rather than increasing marginal utility, and was probably a result of the small number of data points. We retained a linear form to the regression. In future studies, imaginative ways will have to be found to increase this number. For example, the contingent valuation questions could be randomly attached to different scenarios presented in each questionnaire version.

Although the estimates of reduction in time spent in KNP with loss of river function agreed with other measures (see above), we felt that the estimates of change in time spent in KNP with improvements in river quality were unrealistic (e.g. that, on average, people would stay $24 \%$ longer if rivers were in 'ideal' conditions), and these may have skewed this model's results. There seemed to be a discrepancy between those that interpreted the question as purely hypothetical (i.e. nothing would constrain their ability to remain in the park longer), and those that assumed that real-world constraints (such as pre-determined holiday lengths) would still exist. This is, most likely, the result of interviewer bias, or an unclear presentation of the scenario, and attention should be paid to the wording of this question and to giving respondents more time to consider their answers (cf. Whittington et al., 1996). Alternatively, the responses to this hypothetical scenario may actually better reflect peoples' change in utility rather than in their expected change in economically measurable behaviour or expenditure.

In addition, in future applications, the contingent valuation should include the possibility that respondents might change the frequency of visits to the KNP as well as, or instead of, changing the duration of a visit. This would be particularly relevant for local visitors.

\section{Applicability of these valuation methods in resource allocation decisions}

In both EIA and RDM, decision processes which evaluate alternative scenarios for the allocation of resources usually involve decision frameworks such as cost-benefit analysis (CBA) and/or multicriteria decision analysis (MCDA). Both types of analysis involve a comparison of outcomes based on certain criteria. Criteria for valuation in CBAs have traditionally been limited to project costs and benefits and environmental costs or benefits have been excluded as externalities. However, environmental impacts can be taken into consideration in both frameworks. Whereas they have to be expressed in monetary terms to be included in CBA, this is not a necessary prerequisite for their inclusion in MCDA.

This study quantified the tourism and recreational value of rivers of the KNP and component catchment areas. The values obtained do not take into account their total ecological value in terms of the ecosystem functions that the rivers fulfil, other use and non-use values, nor recreational values not associated with the $\mathrm{KNP}$. If CBA is to include environmental costs and benefits of alternative scenarios, then it is necessary to include all types of environmental values ranging from direct use of natural resources to existence values. Some of these values are more tangible than others. Even tourism or recreational value, as measured in this study, contains a mixture of more and less tangible values, ranging from direct on-site expenditure to consumers' surplus. It is the less tangible values such as consumers' surplus and existence value that are more difficult to measure. These are also difficult concepts for most stakeholders and decision-makers to grasp, especially when expressed in monetary terms. As a result, they are often excluded from studies, despite the fact that their value is often a significant proportion of overall value. In fact, these are important values to communicate to policy- and decision-makers.

Because of the dangers (of incompleteness or inaccuracy) inherent in relying solely on CBA, and thus the accurate estimation of value, a preliminary decision framework developed for the RDM process (Turpie et al., 2000) suggests the use of MCDA as an integrative process, with valuation methods such as those developed here being used to supply some of the inputs into this process. MCDA has the advantage of being able to cope with qualitative as well as quantitative criteria in assessing trade-offs in the decisionmaking process (Stewart et al., 1997).

Nevertheless, there may be advantages in being able to quantify criteria, and the use of methods such as those described here may enhance both CBA- and MCDA-based decision processes. However, the methods are often complex (for example, this study of recreational use value alone involved using TCM, CVM, conjoint valuation, GLM, and regression) and surveys can be costly. Whether the results justify this needs to be tested in South Africa over the next few years.

In valuing natural resources, a variety of methods can be applied depending on the types of value to be measured. These methods can be grouped into three main types: market-based methods (e.g. surveys of direct use), those using surrogate markets (e.g. TCM) and those using hypothetical markets (e.g. CVM, Conjoint analysis). In this study we chose tourism/recreational value to illustrate the application of valuation methodology to environmental criteria used in decision processes, because it contains components of value which require techniques from all three main groups of valuation methods. We have demonstrated that it can be relatively straightforward to assess the current total value of a natural amenity (in this case, using market value, TCM and CVM techniques), and that the main complexity lies in evaluating the potential impacts of a change in the resource. The latter requires the use of hypothetical market, or stated-preference, techniques such as CVM or conjoint valuation. To our knowledge, conjoint valuation has rarely, if ever, been applied to this type of problem, but we believe this method has much potential for application in resource allocation decision processes such as EIA and RDM, particularly because it lends itself to flexibility in analysing alternative options. Whereas using CVM to evaluate alternatives requires a priori definition of scenarios, the use of conjoint valuation methods means that scenarios (in particular, the levels of attributes) can be redefined to some extent during the decision process.

\section{Acknowledgements}

This study was funded by the University of Cape Town and the Water Research Commission through the Institute of Natural Resources, University of Natal. KNP provided free entry to the park. We wish to thank Myles Mander of the Institute of Natural Resources for helping with survey design and logistics, and KNP staff for their assistance in providing information for the study, especially Freek Venter for logistical support and ecological advice. Thanks to students of the UCT's Conservation Biology M.Sc. 
Course for their help in survey design and implementation: Sharon Bosma, Daniel Chongo, John Foord, Sarah Frazee, Mathew Hemming, Alina Lengyel, Nonofo Mosesane, Jean Mwicigi, Paul Ndang'ang'a, Genevieve Pence, Bianca Preusker, Domitilla Raimondo, Samuel Soto, Lochran Traill and Ruth Wiseman. Finally, we are grateful for the willing participation of all the tourists and guides interviewed.

\section{References}

ARROW K, SOLOW R, PORTNEY PR, LEARNER EE, RADNAR R and SCHUMANH (1992) Report of the National Oceanic and Atmospheric Administration (NOAA) Panel on Contingent Valuation. Washington D.C. pp1-64.

BISHOP RC, CHAMP PA and MULLARKEY DJ (1995) Contingent Valuation. In: D. W. Bromley (ed) The Handbook of Environmental Economics. Blackwell Publishers, Cambridge. pp 629-654.

BOCKSTAEL NE, MCCONNELL KE, and STRAND IE(1991) Recreation. In: Braden J.B. and Kolstad C.D. (eds). Measuring the Demand for Environmental Quality. Elsevier Science Publishers B.V. 227-270.

BOXALL PC, ADAMOWICZ WL, SWAIT J, WILLIAMS M and LOUVIERE J (1996) A comparison of stated preference methods for environmental valuation. Ecol. Econ. 18 243-253.

CSIR (2000) Guidelines for the use of Environmental Economic tools in Environmental Impact Assessments. Unpublished discussion document.

DOBBS IM (1993) Individual travel cost method: estimation and benefit assessment with a discrete and possibly grouped dependent variable. Am. J. Agric. Econ. 75 84-94.

FREEMAN AM (1993) The Measurement of Environmental and Resource Values: Theory and Methods. Resources for the Future Washington D.C.

GREEN PE and RAO VR (1971) Conjoint measurement for quantifying judgemental data. J. Mark. Res. 8 355-363.

HOF JG and KING DA (1992) Recreational demand by tourists for saltwater beach days: comment. J. Enironv. Econ. Manage. 22 281291.

MACKENZIE J (1993) A comparison of contingent preference models. Am. J. Agr. Econ. 75 593-603.

McGRATH MD, HORNER CCM, BROUWER SL, LAMBERTH SJ, SAUER WHH and ERASMUS C (1997) An economic valuation of the South African linefishery. S. Afr. J. Mar. Sci. 18 203-211.
MITCHELL RC and CARSON RT (1989) Using surveys to value public goods: The Contingent Valuation Method. Resources for the Future. Washington D.C.

MORAN D (1994) Contingent valuation and biodiversity: Measuring the user surplus of Kenyan protected areas. Biodiversity and Conservation 3 663-684.

NAVRUD S and MUNGATANA ED (1994) Environmental valuation in developing countries: The recreational value of wildlife viewing. Ecol. Econ. 11 135-151.

REPUBLIC OF SOUTH AFRICA (1998) National Water Act and Amendments. Government Gazette Vol. 398 No. 19182. Cape Town.

SHULTZ S, PINAZZO J and CIFUENTES M (1998) Opportunities and limitations of contingent valuation surveys to determine national park entrance fees: evidence from Costa Rica. Environ. Dev. Econ. 3 131149.

STEVENS TH, BELKENER R, DENNIS D, KITTREDGE D and WILLIS $C$ (2000) Comparison of contingent valuation and conjoint analysis in ecosystem management. Ecol. Econ. 32 63-74.

STEWART TJ, SCOTTL and ILONI K (1993) Scenario Based Multicriteria Policy Planning for Water Management in South Africa. WRC Report No 296/1/93.

STEWART TJ, JOUBERT A, SCOTT L and LOW T (1997) Multiple Criteria Decision Analysis: Procedures for Consensus Seeking in Natural Resources Management. WRC Report No 512/1/97.

TOBIAS D and MENDELSOHN R (1991) Valuing ecotourism in a tropical rain-forest reserve. AMBIO 20 91-93.

TURPIE JK, MANDER M and JOUBERT A (2000). Framework and Methodology for Incorporation of Economics into Resource Directed Measures and the Strategic Adaptive Management of Water Resources in South Africa. Water Research Commission / Institute of Natural Resources Discussion Paper.

VAN COLLER AL, ROGERS KH and HERITAGE G L (1997) Linking riparian vegetation types and fluvial geomorphology along the Sabie River within Kruger National Park South Africa. Afr. J. Ecol. 35 194212.

WHITTINGTON D, SMITH VK, OKORAFOR A, OKORE A, LONG LIU J and McPHAIL A (1996) Giving respondents time to think in contingent valuation studies: a developing country application. In: Oates WE (ed.) Estimating Economic Values for Nature. Edward Elgar Cheltenham. 